\title{
HAMOTHORAX.
}

\author{
By Col. Sir JOHN ROSE BRADFORD, K.C.M.G., C.B., F.R.S., A.M.S., \\ and Capt. T. R. ELLIOTT, F.R.S., R.A.M.C.
}

Wounds of the chest in warfare may sometimes cause extensive laceration of the lung or of the chest wall without producing a hæmothorax. Such cases are excluded from discussion in this paper, which deals only with the occurrence of a hamothorax.

The two main questions which arise when a medical officer has to deal with a man who has been wounded in the chest are questions which turn upon the dangers of prolonged bleeding and of sepsis. How soon can the soldier be evacuated to the base hospitals? A delay of several days must be interposed at the earliest possible resting-place on the evacuating line if there is a real risk of movement augmenting the internal hæmorrhage to an extent that may be fatal. What is the probability of sepsis ? Is the hæmothorax likely to be infected and soon become an empyema, and is there a risk of the introduction of sepsis if an attempt is made to aspirate an uninfected hæmothorax ?

The experience gained in the South African War inclined surgeons to a most conservative method of treatment. Movement was naturally deprecated when the journeys from one point to the next on the line of communications were so long and trying to the patients. Infection of a hæmothorax was a rarity. Sir George Makins, in his book on Surgical Experiences in South Africa, 1899-1900, states that during the whole campaign he saw only a single case of primary empyema, and this was one which he attributed to infection introduced in an early operation for the removal of a bullet as it lay beneath the skin. On the other hand, secondary empyemata were supposed to have been caused in several instances by aspiration; and there was a general belief in South Africa that aspiration was useless in addition to being dangerous, since the fluid was observed to have accumulated again after the first tapping. Aspiration, therefore, was condemned. Resection of a rib in order to dislodge intrapleural blood-clot was also, and rightly, forbidden, since secondary infections were then certain to be introduced. Primary empyemata did not exist. So it was decided that chest wounds were best left to the natural processes of cure : and the cases recovered very well.

The present campaign in Flanders has changed this teaching. Highvelocity bullets at short range, or tearing fragments of shell, cause greater laceration than was seen in Africa, and the effusion of blood into the thorax is often so large in amount that it cannot very well be left alone. The clothing and the skin of the soldiers are fouled with soil and fæcal organisms, and from this source primary infection is very frequently introduced into the hæmothorax. Hæmorrhage would appear to be, and sepsis most undoubtedly is, a much more serious matter in the prognosis of chest wounds than it was when our Army was last in the field. 
The clinical material upon which the conclusions embodied in this paper are based was abundant. Thanks to the courtesy of the officers of the R.A.M.C., all the cases of chest wound that passed through Boulogne from the first days of November onwards were made accessible to us for study. During this time the base hospitals in Boulogne were about sixty miles from the front, and the journey down by ambulance train from railhead took about twelve hours. Many chest cases arrived on the second or third day after the wound had been received, though others were delayed at some point nearer to the front until the end of the first, or even of the second, week. Until the summer, all convoys, even those destined for most distant bases, passed through Boulogne, and it was the rule for the worst and the moribund cases to be picked out of the trains and left at this town. During this time, therefore, the hospitals grouped around the railway station at Boulogne received the worst wounds, and provided the best opportunity for a study of the fatal results that might follow from an injury of the chest.

Cause of Death. - The figures which we quote were collected in two different ways. In the first place there is a group of results derived entirely from post-mortem examinations. Autopsies were made by Dr. H. Henry on all cases of chest wounds from two hospitals, and also on several cases which had died in transit on the trains. Many of these were never seen by us during life. In addition to the chest wounds, Dr. Henry was engaged in a routine examination of deaths from paraplegia, which naturally included a considerable number of cases with hæmothorax as well, the missile having traversed the lungs to reach the spinal cord. The following are his results :-

Post-mortem examinations were made on 84 bodies with chest wounds. Of these, 69 had an effusion of blood into the pleural cavity. In this group of hæmothorax, 23 died of complications, such as purulent bronchitis, paraplegia, or additional injuries to the abdominal viscera. The remaining 46 died simply from the hæmothorax. But the effusion was found to be infected in 38 of this number, and death in every single one of these had been caused by the infection. Only with certainty in one man, who died on the third day; and perhaps in 7 other doubtful cases where the evidence was incomplete, could the death be ascribed to simple hæmorrhage. Yet many of these 46 men succumbed within the first week of their injury:

From this the conclusion is quite clear. Death from simple hæmorrhage is not to be feared if the patient has survived to the third day; nor does removal to the base introduce any further danger in respect of hæmorrhage after that date.

The second group of statistics is of a different nature, for it comprises only those cases which were seen during life: In this series clinical notes were taken by one of us (T. R. E.) of all those cases which are included in the numbers given. But for this very reason the figures are a little misleading; because, as the work increased in volume, it soon became impossible to keep records of the mildest cases; in which the effusion of blood was small or nonexistent: These were dropped aside, and in consequence the proportion of severe to mild cases is unduly high. No case is described as septic unless an infection was proved to exist by bacteriological examination. The clinical notes fell into two groups : $(A)$ from November to the week of Neuve Chapelle 
in March, during which a fair proportion of even the mildest cases were noted down; $(B)$ from March to July, when only the severe cases were as a rule recorded.

Group $A$ gave a total of 168 cases of hæmothorax. (There were also notes of 27 in which the lung was wounded but there was no effusion.) The hæmothorax was sterile in 114 cases, and 48 of these were so large (generally forty ounces or more) that they had to be treated by aspiration. There were 28 infected cases which survived after resection of a rib. Death occurred in 26 cases with effusion, and in 20 of these death was due to sepsis, only 1 having died, on the third day, as the direct result of simple hæemorrhage from the lungs. The aggregate is 48 septic as against 120 sterile effusions, of which 48 were large.

In group $B$ sepsis is still more prominent. The total was 160 cases of hæmothorax. (In this group only 5 cases of simple wound without effusion were noted.) The hæmothorax was sterile in 86 eases, and of these 41 were aspirated. There were 53 septic cases which survived after resection. There were 21 deaths, and in 16 of these the effusion was septic. There was again only 1 death from simple hæmothorax, and that was complicated by a wound of the heart. The aggregate is 69 septic as against 91 sterile effusions, of which 41 were large.

The entire total gives 328 cases of hæmothorax; 211 were sterile, and 89 of these were so large as to need aspiration. Sepsis was found in 117. Death occurred in 47 cases, of which 36 were septic. Only in 2 deaths was simple hæmorrhage the cause. Infection, therefore, was present in roughly one-third of the cases recorded, and the large effusions were just as often septic as sterile. To obtain approximate percentage figures, one might allow for mild cases of hæmothorax which were seen but not noted down, raising the total to about 450. Infection would then have been found in 25 per cent, and the total mortality for all cases roould be 10 per cent. As regards the cause of death in this mortality figure, it was actually found that 70 per cent died from sepsis, 5 per cent from simple hæmorrhage, and the rest from sundry complications.

This death-rate applies only to hæmothorax, and it represents the incidence in a group of base hospitals to which the severest cases tended to be sent. In the casualty clearing stations nearer the front an almost identical mortality of 10 per cent has been recorded, but this is the death-rate of all wounds of the chest, and it covers chiefly the mortality in the first few days after the wound. No autopsies could be made to determine the actual cause of death in these men. It may be presumed that simple hæmorrhage, the chief cause of death on the field, also claimed a share of the 10 per cent who died near to the front. In the 10 per cent mortality among the survivors who passed through the casualty stations and reached the base, hæmorrhage was negligible, and sepsis took its place as the chief danger to be feared.

The chance of infection has therefore to be considered in every case of hæmothorax. It may develop as acutely as an infective peritonitis, and with almost as rapid a movement to a fatal end. Hence comes the importance of moving the wounded man as soon as possible, after the danger from hæmerrhage has passed away, to a station where the infection can be promptly recognized and dealt with.

VOL. III.-NO. 10. 


\section{STERILE HEMOTHORAX.}

The Effusion.-Post-mortem evidence has shown that in some of our cases the blood came from the vessels of the chest wall, in others directly from the lungs. The exact source cannot be determined in life, and therefore every case should be treated as though the blood had been derived from the lung. Hxmoptysis, early or late, occurs in a great majority; but it cannot be relied upon as a token of the source of the hrmothorax, for it may be merely the result of a bruise of the lung from an extrapleural wound; while on the other hand it has even been absent in some cases where the lung was wounded and the bronchi were ultimately found to contain much blood. The track of the missile through the lung rarely shows much laceration, but there is considerable infarction around it. The missile generally passes right through the soft tissue and is arrested elsewhere.

The bleeding is in all probability fairly rapid, though not often so abundant as to cause faintness in the cases that survive, and the leakage soon comes to an end. Though we saw ten cases within a few hours of their wounds, and a considerable number on the second day, it was only rarely that we met with evidence of a prolonged, or of a late resumption of, hæmorrhage.

There has been much discussion as to the extent to which the effused blood coagulates inside the pleural cavity. Post-mortem evidence is a little unsatisfactory, on account of the clotting that may occur after death. The material that is removed by aspiration from a sterile hamothorax at any time from the fourth day onwards may be :-

1. A brownish-red fluid, which yields a light gelatinous clot in vitro on standing, and contains lymphocytes and endothelial cells. The fluid which separates from the clot is generally tinted by the products of hæmolysis, but it may be a clear transparent yellow.

2. A deep-red fluid, exactly like non-clotted blood, which, however, throws down a very heavy deposit of ordinary red cells on standing, and may fail to give even the lightest of clot in vitro.

3. Masses of soft blackish clot, like jelly, which soon block the needle.

In two cases of aspiration on the sixteenth day, a dark-red fluid was obtained which clotted in vitro to a solid mass. At first the opinion was that in these two examples the blood had remained unclotted in the chest, while still retaining its normal coagulability on removal. Then it became necessary to admit that.in (3) the ordinary processes of clotting must have already taken place within the chest; while (2) was explained by the hypothesis of some peculiar change in the contrary direction which rendered the blood noncoagulable. These contradictions can be avoided by the explanation which is given by Elliott and Henry. From their observations, it appears probable that clotting takes place always-and very early-through the action on the blood of the ferment liberated at the surface of the wounded tissues. The clot may be (a) complete and massive, forming a soft and persistent clot, such as is found in (3) ; (b) massive, but with an early and fairly extensive separation of the ycllow serum from the clot, as in (1); $(c)$ interfered with by the churning movements of respiration, so that the fibrin is whipped out in layers which cover the pleural surfaces, while the serum retains most of the red 
corpuscles in suspension, precisely as is seen with defibrinated blood in a test tube. This corresponds to the state of (2), and the correctness of the explanation is borne out by the observation that aspiration fluids of this class-have been found by direct test to be devoid of fibrinogen.

The pleura reacts to the presence of the blood by a mild inflammation, with a consequent emigration of endothelial cells, lymphocytes, and of polymorphonuclear leucocytes, and with an outpouring of a variable amount of inflammatory fluid which contains fibrinogen, and therefore yields a secondary clot outside the body when the fluid is allowed to stand after aspiration. This secondary gelatinous clot resembles that of an ordinary pleural effusion, and it may even be so dense as to mimic a primary clot.

According to this view of an early coagulation within the chest, the point of leakage will soon be sealed by clot. Post-mortem examinations, indeed, often reveal such a condition, with a layer of compact fibrin adhering to the pleural surfaces and closing the wound, while the cavity is occupied by a red 'whipped' blood which does not clot on standing. The clot tends to lie in masses at the back of the chest and along the paravertebral recess. The lung itself is collapsed by pressure where it dips into the hæmothorax. Above this it is over-distended and emphysematous, so that the upper lobe may actually encroach across the middle line of the chest as the whole mediastinum is displaced laterally by the increase of intrapleural pressure due to the effusion. The largest effusions of 70 to $90 \mathrm{oz}$. generally cause complete collapse of the entire lung against its root; but at times the collapse may be rendered. asymmetrical by the tethering action of old pleural adhesions.

Subcutaneous emphysema is fairly common in these penetrating wounds, and it is difficult to believe that this can develop without some air being also driven from the lung wound into the pleural cavity. Perhaps small collections - of air may be frequent, for it is very difficult to prove or disprove their presence by the ordinary methods of physical examination. Large collections of air together with blood, causing complete collapse of the lung, are undoubtedly rare. In the total series of 328 cases of hæmothorax, only 8 indubitable examples were met with, while there were in addition only 4 cases of complete pneumothorax without blood.

Clinical Features.-The physical signs are as follows : The chest on the side of the hæmothorax moves poorly, the intercostal muscles in the lower half and the diaphragm being largely out of action. The diaphragm remains in a state of atonic relaxation, so that the area of stomach resonance is found to extend unusually high on the left side. This immobility is not caused simply by the wound of the lung, for it only appears with a hæmothorax. The heart is displaced away from the effusion. This displacement is greatest in the first two or three days, before the chest becomes quite immobile, and while the lung has not yet reached its fullest degree of collapse. The percussion note is dull, high-pitched, and resistant over the effusion. Above this, over the emphysematous upper area of the lung, the note is often of a lower pitch and more tympanitic than over the corresponding area of lung on the other side, this Skodaic resonance being at times exaggerated to a surprising degree. The presence of subcutaneous emphysema is at once recognized on palpation, and it introduces a very tympanitic note on percussion which completely 
masks the condition of the deeper strata. Tactile fremitus is abolished over an area slightly less than that of the dullness on percussion. It is often increased over the area of Skodaic resonance; and it is only weakened, not abolished, over the air in a pneumohæmothorax. The breath sounds are generally weak over the emphysematous area, very weak and distantly tubular over the dull area. But sometimes the tubular sounds from the collapsed lung within a hæmothorax are so loud and clear as to suggest, quite wrongly, that the lung is close to the thoracic wall. Adventitious sounds, putting aside those due to subcutaneous emphysema, are rare on the injured side. The vocal resonance is always changed : over the Skodaic area it is increased to a loud buzz; over the fluid the buzz is lost, but there may be bronchophony and whispering pectoriloquy, while ægophony is frequently heard in areas which change from day to day.

At the moment of the wound, the soldier often feels completely winded, and this distress is succeeded by a dyspnoea which lasts for two or three days, or as long as there is a large effusion inside the chest. Hæmoptysis generally occurs, but it is rarely abundant, and it does not often show the colour of fresh bleeding after the first week. The temperature rises to $101^{\circ}$ or even $104^{\circ}$ in the first few days. After that the chart varies with different cases. In the majority the temperature soon falls nearly to normal, oscillating from $98^{\circ}$ to $100^{\circ}$ for the next week or two. But in others it may remain high, or rise again after a preliminary fall. A high level is rarely shown, and the rule is to see regular daily oscillations from $99^{\circ}$ to $102^{\circ}$, or from $100^{\circ}$ even to $104^{\circ}$. No satisfactory cause has been found to explain the difference between these types. The temperature has nothing to do with the state of clotting of the effused blood; and no recognizable micro-organisms have yet been found in the febrile cases which run an aseptic course.

The tongue is clcan or lightly furred. The blanching that would be expected from a loss of 60 or $70 \mathrm{oz}$. of blood is not manifest. Indeed, after the second day the patient does not exhibit the picture of internal hæmorrhage. A very faint icterus may appear towards the end of the first week as the result of absorption from the hæmothorax, but there is never real jaundice. In the second week, the patient feels and looks well, and his face soon regains the aspect of health. Even the largest effusions do not prevent his breathing with fair ease in the recumbent posture.

Differential Diagnosis,-Pneumonia, presumably of traumatic origin, is sometimes diagnosed in mistake for the hæmothorax. The opinion rests upon the combination of fever, dyspncea, and tubular breath-sounds, together with loss of movement on the wounded side. These mimicking physical signs are due to the extreme collapse of the lung, and they form a group closely resembling those which occur in the massive collapse of the lung that may follow an abdominal operation in civil life, where they are also very frequently misinterpreted as being due to pneumonia. The points that prove the hæmothorax are the displacement of the heart, and the absence of fine crepitations. Pneumonic consolidation does occur occasionally in the contralateral lung, and this complication adds to the fever of the hæmothorax: But we have never found unequivocal proof of its occurrence on the side of the hæmothorax. The mimicking signs vanish rapidly when the 
lung is expanded by aspiration of the compressing fluid. Moreover, it has been a striking feature in post-mortems that the collapsed area is generally free from invasion by such secondary inflammations as may have beset the rest of the lungs.

Pneumohamothorax is a wrong diagnosis that is sometimes made when the emphysematous upper part of the lung above an effusion gives a tympanitic percussion-note and weak breath-sounds. In most cases these changes are Skodaic pheromena, as is proved by the increase of tactile fremitus and of vocal resonance in association with them. In addition, the $x$ rays show a radiogram in which the opaque blood has an irregular and slanting upper margin. Where air is present in considerable quantity above fluid, the upper level, as the patient sits erect, is strictly horizontal, and undulatory oscillations can readily be observed in the fluid by the fluorescent screen. This test is decisive, and it can' always be applied, because the clotting in a large pneumohæmothorax, by reason of the greater churning movements, is of the type that yields a fluid 'blood.'

Spreading Collapse.- In an article published a little more than a year ago in this Journal (Vol. I., p. 587), Dr. W. Pasteur described the nature of what he styled "Massive Collapse of the Lungs in association with Abdominal Lesions." In the cases under discussion by him the lung had collapsed during a phase of inadequate respiratory movements, though there was no cause to produce an increase of intrathoracic pressure.

In four quite definite instances we have met with a change which is somewhat comparable to massive collapse. A man's chest is found to be dull to the clavicle, and the signs are those of a very large hæmothorax, except that the heart is not displaced. In a few days the dullness clears up, and the residual signs are only those of a small effusion at the base. We have obtained radiograms illustrating the change. The patients had neither fever nor much purulent expectoration. The probable explanation is that, with imperfect respiratory movements, the usual contrast between collapsed lung below the effusion and emphysematous lung above it is lost, and the state of collapse spreads over the entire lung. Changes of a similar nature, but less extensive, no doubt often occur during the adjustment of a lung to the presence of a hæmothorax, and they are likely to lead one astray when attempting to decide by physical signs whether an effusion has increased or diminished in size. Their clinical importance is that, in the exaggerated examples, they may lead to the wrong opinion that the patient has bled afresh, or that the effusion is so large as to require relief, though it really is small. The criterion is given by the displacement of the heart.

Septic Hamothorax.-So soon as it has been ascertained that a hæmothorax is present, the question arises whether the blood is sterile or infected. The answer may require an exploratory puncture of the chest, and the evidence obtained in this way will be discussed on a later page.

Complications.--Those caused by wounds of other organs in addition to the lungs are generally so obvious that they do not need discussion here. On the right side the liver is frequently injured. Such an injury does not cause jaundice, unless it is accompanied by free bleeding into the peritoneal cavity. In one case under our observation a biliary fistula into a closed hæmothorax 
was caused by a bullet wound. The bile was secreted abundantly, but it remained sterile, and the internal fistula closed in about six weeks, after fifteen pints in the aggregate had been removed by successive aspirations.

Grazing wounds of the heart are probably the cause of a pericardial friction that is often heard when the track of the bullet has gone near the heart and yet there is no infection. This friction may persist for many days, but it is not of any grave importance. No case with a large hæmopericardial effusion has, to our knowledge, survived to reach the base hospitals.

Other complications are those caused by infective processes within the lung itself. The bruising and laceration of the lung around the track of the bullet rarely leads to the development of infected areas, except in cases with paraplegia, and the lung soon heals. But a few cases of laceration without hæmothorax were met:with, in which a gangrenous pneumoniz spread rapidly from the wound and was quickly fatal. Purulent bronchitis of a peculiarly severe type was a familiar malady among unwounded soldiers during the winter fighting. There was no reason to think that this appeared in especial frequency in men with chest wounds; but, when it did occur, the combination of purulent bronchitis and hæmothorax was one'always fraught with great danger. Pneumonia on the other side was an occasional complication, but only once fatal. The other inflammatory complications were, as a rule, secondary results of primary infection of the hæmothorax, and will be mentioned later in that connection.

Treatment.-The presence of a sterile hæmothorax may disable the patient by prolonged fever, by dyspnoea, or by a progressive collapse of the chest wallon the affected. side. The lining layer of blood-clot retards absorption, and a long time must elapse before the compressed lung regains its full expansion. For this reason the free fluid should be removed by aspiration in all cases of effusion which exceed 20 or $30 \mathrm{oz}$ - - that is, roughly, those in which the dullness reaches half way up the scapula. The result of this operation is that the fever disappears either at once or in a few days, the breathing becomes easier, and the mobility of the chest is regained in a few weeks. Out of 89 sterile effusions that were aspirated by one of us (T. R. E.), effusions which were chiefly about three pints in volume, there was in no case any evidence of later hæmorrhage or of any gross re-accumulation of fluid; and only in one instance, to our knowledge, did an empyema develop afterwards. The later history of these men in England has been traced in about one third of the number of cases.

The presence of clot is always liable to hinder the aspiration; and this clotting within the chest occurs so early that it is impossible to attempt removal of the blood before it has taken place. There is, therefore, no advantage in an early aspiration, and from the seventh to the tenth day is a convenient time to choose, provided that fresh hæmoptysis has ceased.. Unfortunately there are no. physical signs known which will serve to indicate whether the blood is congealed in a massive clot that will render aspiration. fruitless, or whether the serum is satisfactorily separated. The massive clot is uncommon. To avoid trouble from dislodged thrombi in the cannula, the needle should be introduced well forward in the axilla at the anterior limit of the effusion, and high up on account of the elevated position of the diaphragm. 
Owing to the great difficulty in arriving at a decision on clinical grounds as to whether the hæmothorax is sterile or infected, a sample of fluid should always be removed at the aspiration for bacteriological study; this can be readily done with the syringe that is used for the local anzsthetic.

There are two disadvantages which may attend a too rapid withdrawal of the fluid. The intrathoracic pressure in these cases may be from 10 to $20 \mathrm{~cm}$. of water higher than normal. A sudden lowering of this by complete aspiration might conceivably cause fresh bleeding from the lung. Actually it is often found to inflict considerable distress on the patient, through a violent fit of coughing, or by inducing acute localized pain, or an indefinable and unbearable sense of tightness in the chest. Pain is occasionally produced when a relatively small quantity of fluid has been withdrawn. This may occur when the pressure has been lowered by only a few centimetres, and it is then probably due to the pull on adhesions around the internal wound. In other cases a high negative pressure and corresponding discomfort are soon reached because the hæmothorax is chiefly in the clotted state and only a little fluid has separated for aspiration.

All these inconveniences may be abolished by the introduction of oxygen so soon as discomfort is noticed. By alternately aspirating the fluid and injecting oxygen, it is possible to empty a chest of all the fluid without causing pain. The oxygen is absorbed in the course of a fortnight. This method of oxygen replacement has been used for some years in the ordinary effusions of civil practice, and an account of the technique has been given by Morriston Davies in this Journal. (Vol. I., p. 9). It is even more useful for a hæmothorax. The simplest of apparatus, without a manometer, will suffice; and the gas is adequately sterilized by passage through a bacterial trap formed by three narrow loops on an open glass tube, the inner surface of which remains wet after boiling. We always made use of Parry Morgan's excellent apparatus, though it is needlessly complex for this particular.purpose.

One may repeat that with ordinary care for asepsis the process of aspiration will never infect a hæmothorax. Those which develop empyemata were infected by the original wound, and the infection can be at once detected when the aspirated fluid is examined with the microscope.

\section{SEPTIC HEMOTHORAX.}

The figures given on a previous page show that a primary infection is so frequent in this war that every hæmothorax with fever must be suspected of sepsis.

Dr. H. Henry studied the bacterial infection in all the septic cases of our series. He found the Pneumococcus, Micrococcus tetragenus, and B. influenza, the denizens of the respiratory tract, in about 20 per cent. The remainder had all been infected from the skin or from fragments of clothing carried in by the missile. These external infections fell into two main groups-those caused by the streptococci and staphylococci, and those due to araerobic gas-producing bacilli of fæcal origin. The latter, either pure or mixed with cocci, were found in nearly half of the infected cases, and as will be seen later, their presence is responsible for a very characteristic clinical picture. 
It has been urged that shell wounds are far more liable to be septic than those from a bullet. There is a preponderance of sepsis in shell wounds, since jagged fragments of casing are almost certain to carry material from the surface into the depths of the tissues; but the difference is not great enough to enable one to use it in estimating the chance of sepsis in any particular case. In 190 sterile cases of hæmothorax, there were 121 bullet, 55 shell wounds; in 77 septic cases which lived, there were $\mathbf{3 3}$ bullet, 38 shell wounds; in 35 septic cases which died, there were 14 bullet, 18 shell wounds. Half of the shell wounds, and rather more than a quarter of the bullet wounds, caused a septic hæmothorax.

Whenever a sinus remains open for long, and air and blood leak to and fro through it from the pleural cavity, the hæmothorax invariably becomes infected from outside. Inasmuch as in these cases the movements of respiration do undoubtedly suck infection into the pleural cavity, it might fairly be urged that many of the examples of septic hæmothorax with a closed wound were caused, not by a primary contamination from dirt carried in by the missile, but secondarily and later through a channel which subsequently became closed. If this explanation were true, then, since movements of transport augment the dyspnœa of these patients to a considerable extent, it might be expected that sepsis would be found in a higher percentage of the men who reach the base on an early date after their wound than in those transported later. Actually there is no such difference. Of 136 cases of sterile hæmothorax, 73 arrived at Boulogne on the third day or earlier, 30 on intermediate days, and 33 on the seventh day or later ; of 65 septic cases which survived, 27 arrived on the third day or earlier, 14 on intermediate days, and 24 on the seventh or later; of 28 septic cases which died, 12 arrived on the third day or earlier. These figures prove that early transport did not increase the incidence of infection; and they suggest that the septic cases became ill at so early a date that on clinical grounds they were probably separated from the rest and delayed longer at the clearing stations.

The contaminating organisms are introduced into the hæmothorax either together with the missile, or later by insuction from an open sinus, or from the respiratory tract. Since the blood clots rapidly after effusion, those entering with the missile may chance to be completely buried inside clot. The others will as a rule be rapidly disseminated through the free fluid. But inasmuch as the pleura is coated with clot, there will often be an interval of many days before pus cells emigrate from the inflamed surfaces in sufficient number to make the hæmothorax frankly purulent. During this interval the microbes may be multiplying freely in the fluid and hæmolysing the red corpuscles; or they may be shut off inside clot, so that their free escape is delayed. It is important to realize the fact that the pool or marshy collection of dead blood may be heavily infected and yet almost free from pus, so that to the naked eye its appearance raises no suspicion.

Clinical Features.-The clinical features which suggest infection are enumerated below. It will be evident, from the saving clauses which follow each item, that no single feature, nor even the complete combination of all of them, is adequate to justify on clinical grounds a certain opinion that infection is present. All may be imitated by a sterile hæmothorax, and the ultimate 
proof can only be obtained by exploratory puncture and bacteriological examination of the fluid.

1. Fever, developing progressively, or sustained at a steady high level, or with widely irregular excursions of temperature. A sterile hæmothorax may be accompanied by fever lasting as long as three weeks, but the daily oscillations then, as a rule, show a regular uniformity.

2. A rapid pulse of 100,120 , or even higher. But severe infection may be present with a pulse of only 80 or 90 .

3. Dyspnoea, which is out of proportion to the physical signs, and increases instead of diminishing.

4. A furred tongue, which tends to be dry and brown with the streptococcal infections. The anaerobic bacilli do not influence fur on the tongue.

5. Sleeplessness. Mild delirium marks a grave and usually hopeless infection.

6. The appearance of pain and tenderness in the side as the pleural inflammation develops. That caused by fractured ribs or by subcutaneous emphysema must be excluded.

7. Vomiting invariably means that abdominal organs have been injured as well as the lungs. But diarrhœe of an offensive nature, and presumably of toxic origin, is occasionally seen as a late result of a septic hæmothorax.

8. The development of a contralateral dry pleurisy or of a pericarditis. Pleurisy is occasionally present though the hæmothorax remains sterile. Pericarditis is a rare complication of a septic hæmothorax, while pericardial friction is often caused by a small, sterile hamopericardium.

9. The physical signs of a septic hæmothorax in themselves do not differ from those of a sterile effusion, except in the cases where anaerobic bacilli are present. These cases are numerous, and they offer some features which require special description. The signs are caused by the slow or rapid development of malodorous gas as the bacilli grow in the effused blood : $(a)$ The heart may in a couple of days undergo a great increase of displacement. (b) Over the bubble of gas, and within the area of dullness due to the hæmothorax, there is heard a peculiar 'cracked pot' note on percussion; this is lower in pitch than the tubular note that is sometimes elicited over compressed or solid lung, and the distinction is further aided by the fact that breath sounds are absent over the first and audible over the second. The sign is sometimes mimicked by the tympanitic note of a distended colon or stomach, heard at an unusually high level on account of the relaxation of the diaphragm. Inasmuch as the gas may develop rapidly at any time after the third or fourth day, and the patient in consequence may show great respiratory distress and collapse without high fever, these cases are liable to a disastrous error in diagnosis, which regards them as an increasing pneumohæmothorax that can only be saved by rest and morphia.

The features named above may raise the suspicion of infection, a suspicion which should be entertained in every case of hæmothorax where the general condition has not definitely improved by the fourth day after the wound. They cannot confirm it, and the decision is only attained by use of the exploring needle. Infection in the sample is proved by :-

1. A heavy deposit of pus on standing. Microscopic pus is insufficient proof, since it may be met with in a sterile effusion.

VOL. III.-NO. 10. 


\section{THE BRITISH JOURNAL OF SURGERY}

2. An extremely offensive odour, like that of rotten eggs or fæces; which is invariably due to the presence of anaerobic gas-producing bacilli.

3. The detection of organisms, either in a direct film or on culture. These may be found though the fluid resembles perfectly sweet blood; and, indeed, the worst streptococcal cases generally yield in the early days a fluid of a rich red colour, owing to extreme hæmolysis of the red cells.

The occlusion of organisms within a mass of clot will sometimes introduce difficulties in their detection when the chest is explored at an early date and before the free fluid is infected. This was so frequently the case with the anaerobic gas-producing bacilli, that it appeared probable that the delay might be due to some additional factor governing the rate of their growth in the blood. In nearly 20 per cent of the infections by these bacilli the bacteriological report on the first sample of fluid, removed on the fifth or sixth day, was that it was sterile. Yet all these cases appeared clinically to be septic, and a second exploration three or four days later found, as a rule, abundant infection. An extract from a case may be quoted which illustrates the steps of this pathological process.

6th day.-Signs of moderate hæmothorax. $X$ rays showed fragment of shell close to tenth rib.

8 th day.-Pulse rapid, but temperature only $100^{\circ}$. Chest explored : clear, yellow serum, with fine spider-web secondary clot, a few polymorphs, and no organisms:

11th $d a y$-Looks septic. Aspirated: only 15 ounces of reddish serum, with dense secondary clot, a very slight deposit of pus, and here and there a Bacillus perfringens.

15th day.-Resected. Capt. Kelly found the shell fragment lying in a purulent pocket of offensive clot, while this in its turn was enveloped by old soft blood-clot. Rapid recovery.

Differential Diagnosis.-In a febrile case of 'hamothorax this will in the first place be concerned with excluding purulent bronchitis,_contralateral pneumonia, or septic wounds elsewhere as the cause of the ill progress of the case ; and in respect of the hæmothorax itself, it will rest with the exploring needle to decide whether this is septic or sterile, and whether an apparent pneumohæmothorax is or is not caused by gas-producing bacilli.

Treatment.-Early recognition of infection is important. The case should not be allowed to drift on until the effusion assumes an obviously purulent character. Delay in the removal of the infected fluid reduces the patient's strength; it causes more lasting injury to the chest, through the greater thickening of the inflamed pleura; and it may even be fatal, by allowing the infection to develop into a septicæmia, or to spread into a contralateral empyema and pericarditis.

The infected fluid may be removed by aspiration. This leaves infected clot behind, and suppuration with a fresh accumulation of fluid goes on indefinitely. Some forms of infection by anaerobic bacilli may die down in a few weeks; but the probability is much greater that the patient himself will die first, if the infection is not given free exit. In the first months of the war we endeavoured to postpone opening the chest, and tried in a few cases to treat the infection by repeated aspirations. None recovered fully until a rib was resected, and the mortality in the septic cases was higher than at a later time, 
when it became the routine to explore every suspicious case and open the chest as soon as infection was proved. The figures to which reference has already been made illustrate the disadvantage of tardy treatment. In group $A$-that is, up to March-20 septic cases died and only 28 recovered; perhaps 11 of these deaths might have been avoided. In group $\boldsymbol{B}, \mathbf{5 3}$ septic cases lived and only 16 died; of the latter all but three or four were hopeless infections.

There may be reasons to delay operation in the presence of mild infections caused by the Pneumococcus, $M$. tetragenus, and certain Gram-negative diphtheroids; but every hæmothorax that contains streptococci, staphylococci, influenzal or anaerobic bacilli, should be treated as soon as possible by resection of a rib. When the effusion is very large, it is best to evacuate it by a preliminary aspiration. An ordinary wide resection close to the diaphragm yields fairly good results. So far as we have been able to trace the patients in England, all have recovered in three or four months, and more extensive operations for chronic empyema have not been required.

Two points to be considered in the surgery of infected hæmothorax arehow to deal with septic clot, and how to prevent secondary infections from invading the cavity. The difficulty of retained clot makes drainage through a slit in the intercostal spaces unsatisfactory, though this method has the advantage of aiding expansion of the lungs and checking secondary infections. The best recovery that we have seen was, as a matter of fact, in a case of mixed infection by streptococcus and gas bacillus which was treated by slit drainage. But in two others, death was directly caused by the faults of the method; so that it appears to us unwise to use it. When the infection is gross and mixed, and the contained fluid is abundantly purulent, it is best simply to insert a large tube and await the results of drainage. Rough handling of the inner pleural surfaces may break down inflammatory barriers and light up a fatal septicæmia. After a few days the cavity can be flushed out with hydrogen peroxide and some -weak antiseptic, which will dislodge the septic clots. The introduction of Wright's hypertonic saline tablets caused smarting, and they did not produce any appreciable improvement in the cases in which they were tried by us.

A simple infection by staphylococci or by anaerobic bacilli may be treated by a method similar to that which Cantlie used for drainage of a liver abscess, and which other surgeons have employed for empyemata. The cavity is wiped free of clot by gauze mops. A long tube is sewn in by air-tight closure in successive layers of the pleura, muscles, and skin; and the end of this tube drains just under the surface of a bottle of weak carbolic placed on the floor.

The development of a purulent bronchitis is a dangerous complication of these infections, and its onset requires the free use of expectorant medicines.

Air in the chest, either as a complete pneumothorax or as a large pneumohæmothorax, sometimes raises a probleni of great clinical difficulty. Fortunately only 3 out of the 12 cases that we have seen were infected. If infection is present, and it is allowed to remain untreated for long, the thickening of the pleura over the completely collapsed lung will check expansion later, and a huge empyema cavity will be the lasting result. To prevent this, the air and fluid should be removed by aspiration as early as possible, and an attempt made to establish adhesions between the lung and the chest wall. Resection should 
not be performed until a later date. The air leak from the lung is generally found to be closed by the tenth day, and aspiration can then be successfully used. A manometer is needed with the aspirating apparatus in these cases, since the development of a negative pressure under suction gives the required proof that the air is no'longer leaking from the lung.

Prognosis.- Infections by anaerobic bacilli often make an excellent recovery. The grave symptoms shown are not so much toxic as of a mechanical nature, owing to the rapid development of gas; and the patient rarely, if ever, exhibits the thready pulse, waxy yellow face, ${ }^{*}$ low temperature, and repeated vomiting which are seen in poisoning when a limb is the seat of severe gas gangrene, and which almost invariably presage death. Staphylococcal infections also do well. Worst of all are the acute streptococcal cases, which may rapidly produce a hopeless septicæmia. In group $B, 28$ recoveries were seen in men infected by gas bacilli, and 7 deaths; while 8 pure streptococcal cases lived, and 3 died.

\section{SUMMARY.}

1. The total mortality of chest wounds which reach the base hospitals is 10 per cent.

2. Simple hæmorrhage never causes death after the third day. Sepsis is the main cause of the mortality from this time onward.

3. Primary infection of a hæmothorax occurs in 25 per cent of the effusions, and it is fatal in about one third of the infected cases.

4. The effused blood in a hæmothorax clots rapidly in all cases, but the type of clot varies.

5. A sterile hæmothorax should be emptied by aspiration, except when it is of small size.

6. Infection should be suspected in all cases which are not progressing favourably after the fourth day. It cannot be diagnosed with certainty on clinical features alone; a sample of the fluid must be withdrawn and examined bacteriologically.

7. A hæmothorax fluid which looks red and innocent may none the less be heavily infected.

8. The chest should be opened in all cases of infected hæmothorax, and as soon as possible.

9. The signs of air as well as blood in the chest may be caused by foul gas evolved in the course of an infection by anaerobic bacilli. Immediate resection is then required.

10. A complete pneumothorax, or a large pneumohæmothorax due to air leak from the lung, is not often infected. If infection is present, an attempt should be made to expand the lung again by aspiration before rib resection is performed.

- See Fig. 39, p. 117, in the issue of this Journal for July, 1915. 